\title{
The ESA Education Programme and its ESA Academy
}

\author{
Hugo Marée, Piero Galeone, Alexander Kinnaird \\ Education Office, European Space Agency \\ ESTEC, Noordwijk, The Netherlands \\ ESA.Academy@esa.int \\ Natacha Callens \\ Education Office, European Space Agency \\ ESEC-Galaxia, Transinne, Belgium \\ ESA.Academy@esa.int
}

\begin{abstract}
The European Space Agency's Education Programme, composed of the Primary and Secondary STEM Education Programme for younger students, and the ESA Academy Programme for university students, is strongly committed not only to inspire, but also to actively engage students. The Primary and Secondary STEM Education Programme's aim is to use space as a teaching context to enhance youngsters' literacy, skills and competences as well as to develop the pupils' core values and attitudes in STEM disciplines, and to inspire and to motivate them to pursue studies and careers in the STEM sector. The ESA Academy, the overarching education programme for university students, uses space as the subject, and is designed to equip the next generation of professionals working in the space sector with 21 st century skills and competences, with the objective of enhancing their employability, and stimulating their creativity, innovativeness and entrepreneurship.
\end{abstract}

The ESA Academy encompasses a portfolio of hands-on 'Space' projects ranging from scientific and technologydemonstration experiments to be run on a number of different professional platforms, to small satellite missions such as CubeSats; complimented by a varied portfolio of training sessions given by space professionals coming from all fields of ESA's expertise, as well as from space industry and academia.

Every year hundreds of students participate in ESA Academy's activities, with students participating in launch and experiment campaigns conducted at state of the art facilities located at several centres of excellence around Europe, and amassing an impressive portfolio of space-related and research experience.

In order to be eligible to participate in the ESA Academy programmes, students must be nationals of one of the 22 ESA Member States, or Canada or Slovenia. Operating with students coming from across 24 different states and at different levels of their university studies, comes with a unique set of challenges, including, but not limited to, interacting with different national academic approaches, different academic schedules, student engagement levels, gender and inclusiveness, and team funding. The Education Office has risen to these challenges and has developed a comprehensive and inclusive programme framework, which continues to develop as new challenges and new opportunities are identified.

The ESA Academy is moving forward with the confidence that the future generations of space professionals in the ESA Member States may benefit from getting the best training and hands-on experience to support the future of the European space sector. The ESA Academy aims to reinforce, and even to further develop, its offering of programmes and training sessions over the coming years.

Keywords- ESA, Tertiary Education, Hands-on activities, Training and Learning, University students, Education, Extracurricular.

\section{WHAT IS THE ESA EDUCATION OFFICE?}

The ESA Education Office organises and conducts educational activities for students (i.e. not for professionals). It develops the Agency's education policy and ensures its implementation. Furthermore, the Office organises and manages education activities in collaboration with other ESA directorates, with the goal to federate all ESA educational activities, and to become the single point of contact for the outside world for all the Agency's 'education matters' [1].

\section{WHAT IS THE PURPOSE OF THE ESA EDUCATION OFFICE?}

The ESA Education Office is responsible for developing and implementing ESA's corporate education policy, which is designed with the purpose of supporting Europe's need of encouraging an increasingly knowledge-based society by motivating young people to enhance their literacy in science and technology, including associated applications, and to pursue careers or research in these fields, in particular in the space domain. To this end, it collaborates with ESA Member States' institutions to attract the best talents to space activities [1]. 


\section{WHERE DOES THE EDUCATION OFFICE SIT WITHIN THE ESA FRAMEWORK? AND WHERE DOES IT SIT WITHIN THE OVERALL EUROPEAN SPACE EFFORT?}

The Education Office is part of the ESA Director General's Services, and has strong links with all ESA directorates. Many Education Office projects are organised in partnership or collaboration with other ESA directorates, national space administrations, European space industry, national administrations in charge of formal education, and academic institutions. The ESA Education Office periodically reports to the ESA Council and to the Advisory Committee on Education (ACE), the latter of which is composed of representatives from all ESA Member States, in this way ESA Member States, as stakeholders, are debriefed and may offer their feedback.

The beneficiaries of the ESA Education Office activities may be regarded to be both the direct 'participants' (i.e. the students and the teachers which partake in the Office's initiatives), as well as the European space industry and organisations in general, which benefit from the increased motivation and literacy of their future workforce.

\section{WHY AND WHEN WAS THE EDUCATION OFFICE ESTABLISHED?}

Education was included as one of the fundamental activities of ESA from its very conception in 1975. The foundation document of the Agency, the ESA Convention [2], lays out education as one of the mandatory activities, and thus one that all Member States shall participate in. Consistently with its mandate, the Agency has long been involved in various education activities.

The Education Office itself was formally established in the late 1990s [3], followed shortly by the implementation of the Advisory Committee on Education (ACE), a forum of education experts representing all ESA Member States, which had its first meeting in 2001 [4], and that was definitively established in 2002 [5].

The mandate of the Education Office has remained largely unchanged since its establishment, remaining consistent to its declared initial objective to: "coordinate a European Space Education programme aimed at challenging and motivating a large number of young people through active involvement in exciting projects in order to enhance their literacy in science and technology in general, and space related matters in particular" [3].

The initial set of initiatives of the Education Office included the European Student Moon Orbiter (ESMO), the continuation of parabolic flight campaigns for student experiments, and the establishment of European Space Education Resource Offices (ESEROs). In the following years the Education Office was involved in educational satellite launches (SSETI Express, 2005 [6], YES2, 2007 [7]) and engaged in a considerable expansion of its portfolio of hands-on programmes, see section $\mathrm{X}$.

Building upon the heritage from the many educational initiatives undertaken in the past, the ESA Education Programme formally took shape in 2004, with the introduction of the "ESA Education Policy" ESA/ADMIN/IPOL(2004)8 which established the founding principles to implement the ESA Education Programme [1].

\section{WHERE IS THE ESA EDUCATION OFFICE BASED? AND WHAT ARE THE FACILITIES IT USES?}

The bulk of the ESA Education Office's activities are coordinated from two sites, the European Space Research and Technology Centre (ESTEC) in the Netherlands, and the European Space Security and Education Centre (ESECGalaxia), in Transinne, in Belgium. However many activities take place in other places distributed around all Europe, see section $\mathrm{X}$.

The Education Office organises and hosts various activities at both ESTEC and ESEC-Galaxia, such as teacher training workshops, training and selection workshops for university student teams, training and learning sessions (mostly at ESECGalaxia), and technical work, such as CubeSat testing (at ESEC-Galaxia).

At the ESEC-Galaxia site, the ESA Education Office has established dedicated infrastructure consisting of:

- A Training and Learning Facility (TLF), which can also operate as an educational Concurrent Design Facility (CDF).

- An e-Technology Laboratory for teacher training

- A CubeSat Support Facility (CSF)

The TLF is a modern technical facility, which is capable of hosting up to 30 students and 8 trainers for various types of training sessions, and is equipped with smart boards and networked computers for interactive learning. Further information can also be found in the 3rd SSEA conference paper "The ESA Academy's Training and Learning Programme", Marée et al.

The CSF consists of an ISO 8 clean room laboratory to support small satellites integration, inspections, and testing, equipped with a thermal vacuum chamber and a $20 \mathrm{kN}$ electrodynamic shaker.

\section{HOW IS THE EDUCATION OFFICE ORGANISED?}

In its current set-up, the Education Office consists of two units, the STEM (Science, Technology, Engineering and Mathematics) Education and Outreach Unit, for the Primary and Secondary school level and outreach activities, and the ESA Academy Unit, for the university education level.

\section{WHAT ARE MAIN ACTIVITIES OF THE STEM EDUCATION AND OUTREACH UNIT?}

The STEM Education and Outreach Unit carries out a broad range of activities, aimed at offering education and training opportunities for primary and secondary school teachers and pupils, as well as offering a backbone of outreach services conceived to support not only primary and secondary education, but also the Education Office as a whole.

The approach undertaken to organise the primary and secondary education activities is based on the concept that "Space is the Learning and Teaching Context" which is utilised 
to create educational activities aiming at teaching subjects related to all STEM disciplines.

The activities of the Primary and Secondary STEM Education and Outreach Unit are built around the programmatic backbone consisting of the ESERO Programme.

The ESERO Programme is conducted in partnership with ESA Member States' national space administrations and with their national administrations in charge of formal education, and it aims at developing and maintain a network of national and regional "European Space Education Resource Offices", which shall soon cover all ESA Member States.

The ESERO offices have assigned the task to provide both teacher training and space-related STEM classroom resources, tailored to national education curricula.

Further to coordinating the activities of the ESERO offices, the primary and secondary education activities of the STEM Education and Outreach Unit encompass the following:

1. Teacher training

ESA Education develops several different activities to support the integration of space topics in the classroom. ESA provides regular teacher training workshops, held either at ESTEC, and/or at ESEC-Galaxia, and supports the additional teachers training offered at Member States level by the ESERO offices.

2. School projects

The STEM Education and Outreach unit manages an attractive (and still expanding) portfolio of educational and interdisciplinary initiatives that aim to help young people increase their STEM competences and skills, including scientific methodology, teamwork and critical thinking. These include the creation of original material for classroom resources, and projects such as CanSat competitions, the Moon Camp Challenge, and Climate Detectives. Most of the products and activities created as school projects are also offered or shared with the ESERO offices, in order to maximise the educational return.

3. ESA Education outreach initiatives

The outreach activities provide on the one hand, general outreach about all ESA Education activities (delivered through the whole ESA Education web portal, social media and other platforms), and, on the other hand, to form the bridge between the primary education projects and their target of students and teachers. These latter activities include the production and maintenance of the ESA Kids website, which includes the management of the ESA Kids mascot, Paxi.

\section{WHAT IS THE ESA ACADEMY? AND HOW IS IT ORGANISED?}

The ESA Academy Programme constitutes the ESA Education Office's 'offer' for university students.

Like the Education Office in general, the ESA Academy is designed to complement academic education, and to enhance students' educational experience by allowing them to benefit from a substantial transfer of practical and theoretical knowledge from space professionals.

Correspondingly to the approach adopted for Primary and Secondary Education ("Space is the Learning and Teaching Context"), the approach for ESA Academy is "Space is the Subject", meaning that all programmes and activities offered by the ESA Academy are directly space related.

The whole portfolio of opportunities offered to university students constitutes the ESA Academy Programme, which is based on two interconnected pillars:

1. Training and Learning Programme

The Training and Learning Programme (TLP) created and delivers a portfolio of training sessions for university students, typically lasting 4-5 days each, conducted at a dedicated Training and Learning Facility (TLF). See section IX

2. Hands-on Programme

These include the full participation of university students in all aspects related to space projects. Students are engaged in designing and developing small satellites and/or experiments that can be operated on various platforms, such as balloons, sounding rockets or parabolic flights. The hands-on programmes often include projectrelated workshops and training offered by experts. See section $\mathrm{X}$

Further opportunities offered to university students (individual or teams) consist in:

1. Accessing test facilities

The student teams engaged in the hands-on programmes are supported with access to professional test facilities, located at ESEC-Galaxia, at ESTEC, or, sometimes, at other premises.

2. Participation in conferences and workshops

ESA's Education Office supports student participation in conferences and workshops, including the regular meetings of ELGRA (European Low Gravity Research Association) Symposium and the International Astronautical Congress.

\section{What IS The Training AND LEARning Programme?}

The Training and Learning Programme offers a portfolio of 45 day training sessions on disciplines encompassing many fields of space expertise. These training sessions are developed and delivered by experts, who are specialists in their own specific domain. These trainers are usually ESA employees or retirees but may also be specialists from other space agencies, academic institutions, universities or space industry. Up to 20 training sessions are organised every year at the TLF.

The TLP offers students the chance to complement their university led education with additional training in subjects which may not be covered by their traditional university curricula. The ESA Academy coordinates and funds the development and the delivery of the training sessions, as well as sponsors the travel of the selected students (ceilings may 
apply), including the accommodation and meals for the duration of the training session. Up to 30 students participate in each session.

The full list of training session, including details on how to apply are available on the ESA Education website: www.esa.int/Education/ESA_Academy/Current_opportunities. Further information can also be found in the 3rd SSEA conference paper "The ESA Academy's Training and Learning Programme", Marée et al.

In addition to supporting the conduct of the training sessions of the TLP, the TLF is also utilized to support the conduct of training courses or workshops specifically dedicated to the student teams engaged in the hands-on programmes (for instance workshops on lessons learned from the different programmes, and/or to share in-flight experience).

\section{WHAT ARE THE HANDS-ON PROGRAMMES OF THE ESA ACADEMY?}

The hands-on programmes of the ESA Academy are designed to give students, usually organized in teams, the opportunity to put their education into practice, by engaging in real space projects. This gives them the opportunity to experience the full space project life cycle, starting from the definition of their mission or experiment concept, and passing through the preparation, the submittal, and the defence of their proposal, and, if selected, by engaging in the design, development, manufacturing, assembly integration and testing, and conducting the experiment or satellite mission operations, and analysing the results. Finally, the students are also encouraged to present their projects and their experience at international conferences and in scientific or technical magazines or journals. In general ESA Academy sponsors individual students, or teams (depending on the programme) to attend the various events and reviews associated to the programme in which they have been selected to participate, as well as it offers the launch or access to the platforms where the experiments are operated. The ESA Academy also provides support in terms of offering technical mentoring and by reviewing the students' documentation in conjunction with the major review milestones. In general, student teams are responsible for gathering the funds for the development and procurement of their own hardware.

In a few cases testing is also offered.

In general, participation in the programmes is through competitive selection. Student teams or individuals are invited to submit proposals, and may be invited to participate in further selection events (workshops or teleconferences) before the final selection is made.

\section{A. European Student Earth Orbiter (ESEO)}

ESEO is an educational micro-satellite. ESEO follows on from the SSETI mission (launched 2007); it was initially conducted concurrently to the deferred ESMO mission (put on hold in 2012).

University student teams have been engaged in ESEO during the whole project lifecycle, since the definition of the mission concept up to launch and mission operations. The student teams were supported throughout the project with reviews carried out by ESA and industry experts, as well as by participating in dedicated training sessions, seminars, and workshops on different aspects of the ESEO mission.

The satellite is around $50 \mathrm{~kg}$, with a geometrical envelope of about $33 \times 33 \times 63 \mathrm{~cm}$ (plus antennas).

In the Phase $\mathrm{C} / \mathrm{D} / \mathrm{E}$ (the final part of the ESEO Programme), student teams from 10 different universities in eight member states developed different equipment of the spacecraft, including the whole payload complement, and contributed to several system level tasks. Students were involved in the spacecraft assembly integration and testing, and in the definition of the mission operations.

The university student teams were coordinated by an industrial prime contractor and system integrator, ALMASpace (itself a university spin-off), that in 2015 become part of SITAEL S.p.A. The university student team contributions to ESEO include the on-board electrical power distribution unit, an L-band radio amateur transmitter, an S-band transmitter, a GPS, optical cameras, a Langmuir Probe and a Tritel sensor, a deorbiting mechanism, an attitude determination system, the Mission Control Centre and its related ground station, a back-up mission control ground station, and a ground station dedicated to receiving the s-band transmissions.

ESEO was launched on the 3rd of December 2018.

\section{B. Fly Your Satellite! (FYS)}

The FYS Programme supports university student teams engaged in the design, assembly integration and testing, launch and operations of CubeSats.

The teams participating in the FYS Programme receive specialists' supervision in conjunction with project reviews, as well as specific training sessions, support for testing (expertise and/or access to test facilities), and eventually the launch opportunity. The university CubeSat teams engaged in the FYS Programme have the opportunity, under the supervision of ESA specialists, to get acquainted also with the methodologies and standards adopted by ESA in its programmes, and get the opportunity to familiarise with the standards and requirements applicable to CubeSat missions (tailored, as needed).

FYS is a recurrent programme, which is now entering its third edition. The first edition ran from 2013 to 2016, and supported six university built CubeSats. Three of the selected Cubesats were launched in April 2016, and another one was deployed to orbit from the International Space Station in October 2015. The currently ongoing second edition of FYS (started in 2017), is supporting six teams, which at the moment are preparing to enter the testing phase of their satellites.

The CubeSats participating in FYS may be launched on a variety of different launchers, including being deployed to orbit from the International Space Station (ISS).

A FYS team consists of at least eight students, at least four of which should be at master's level or higher. The length of programme participation depends on the entry level of the CubeSat, but it is typically expected to be about 3 years.

At the time of writing, the call for applications for the third FYS edition is open until the 13th of October 2019, and it is dedicated to CubeSat teams at 'entry level 2', i.e. those with a 
design mature enough to proceed to prepare the assembly integration and testing campaign.

\section{Spin Your Thesis! (SYT)}

The SYT Programme supports university teams through the design, testing and operation of experiments in a hypergravity environment making use of ESA's Large Diameter Centrifuge (LDC) located at ESTEC. Experiments may be operated under the acceleration of 1 to $20 \mathrm{~g}$, for periods of 'minutes' up to 2.5 days.

Typical experiments include investigations in biology, biochemistry, fluid dynamics and materials sciences.

A SYT team consists of two to four students studying at master's level or higher. As with all 'Your Thesis!' programmes the experiment should also be an integral part of the student's syllabus. Each year typically two teams are selected to participate. The duration of one cycle of the programme is approximately 1 year (from selection until experiment results).

The SYT Programme has been running since 2010, and is now entering its 11 th cycle. At the time of writing, the call for proposals for the next edition of SYT is open until the 2nd of December 2019.

\section{Spin Your Thesis! - Human Edition! (SYT-HE)}

The SYT-HE Programme supports student teams through the design and realisation of non-invasive experiments performed on human test subjects exposed to an increased gravity environment.

The test subjects may be asked to perform certain body movements or exercises. The programme makes use of the Short Arm Human Centrifuge of the DLR's envihab-facility, based near Cologne (Germany).

A SYT-HE team consists of four to six students studying at bachelor's level or higher. The duration of one cycle of the programme is approximately 1 year (from selection until experiment results).

The first cycle of SYT-HE took place in 2018, with three teams participating.

\section{E. Drop Your Thesis! (DYT)}

The DYT Programme supports student teams through the design, testing and operations of an experiment to be performed in micro-gravity conditions. This programme utilises the ZARM drop tower, in Bremen (Germany), where experiments can experience micro-gravity conditions at 10-6 g for periods of either 4.74 seconds, or about 9.3 seconds (depending on the 'launch mode' utilised in the drop tower).

A DYT team consists of two to four students. Each year typically one team or two teams are selected. The duration of one cycle of the programme is approximately 1 year and 4 months (from selection until experiment results).

DYT has been running since 2009 and is now entering its 12 th cycle. At the time of writing, the call for proposals is open until the 20th of October 2019.

\section{F. Fly Your Thesis! (FYT)}

The FYT Programme supports student teams through the design, testing and operation of an experiment to be conducted in 'weightless' conditions, on board parabolic flights. This programme makes use of the Novespace Airbus A310 Zero-G aircraft, operated from Bordeaux. The experiments may be operated automatically, or manually by the experimenters (who may also fly onboard the aircraft), and are exposed to 31 parabolas per flight, with three flights per each parabolic flight campaign. Each parabola exposes the experiments to variable acceleration levels, cycling between about $+/-2 \mathrm{~g}$ (soon before and after the weightlessness period of the parabola), and about $+/-0.05 \mathrm{~g}$ during the weightlessness period, which lasts around 20 seconds per parabola.

Experiments conducted during the FYT campaigns have included a large variety of research areas, including fluid physics, material sciences, human physiology, neurophysiology, and psychology, as well as technology demonstrations performed as precursors to spaceflights.

A FYT team consists of four or more students, studying at master's level of higher. Each year at least two student teams are selected to participate. The duration of one cycle of the programme is approximately 1 year and 6 months (from selection until results).

FYT has been running since 2009 and it is now entering its 7 th cycle. At the time of writing, the call for proposals is open until the 6 th of October 2019.

\section{G. Orbit Your Thesis! (OYT)}

The OYT Programme supports student teams through the design, testing and operation of a small experiment to be operated on board the ISS for up to four months.

Experiments are to be conducted in the "ICE Cubes" facility, developed and operated by Space Applications Services.

The OYT Programme started in December 2018, with the selection of one experiment, which is due to be launched to the ISS in April 2020. OYT is expected to become a recurrent programme. The duration of the first cycle is expected to be approximately 2 years (from selection until end of operations).

\section{H. Rocket/Balloon Experiments for University Students (REXUS/BEXUS)}

The REXUS/BEXUS Programme is realised under a bilateral agreement between the Swedish National Space Agency (SNSA) and the German Aerospace Centre (DLR), and supports student teams through the design, testing and operation of their experiments to be flown on a sounding rocket or a stratospheric balloon.

The Swedish share of the payload has been made available to students from any ESA Member State (plus Canada or Slovenia), through an agreement with the ESA Education Office. DLR, SSC, ZARM and ESA all provide technical support to the student teams.

Two rockets and two balloons are launched each year, reaching approximately $80 \mathrm{~km}$ and $30 \mathrm{~km}$ respectively. If 'de-spun', during their ballistic flight the rockets can provide up to 2 minutes of reduced gravity, while the balloons may remain at their float altitude for 1-5 hours. 
A REXUS or BEXUS team consists of at least four students, and each year between eight and 12 teams are selected for the ESA/Swedish part of the programme. The duration of one cycle of the programme is approximately 1 year 2 months for BEXUS experiments and 1 year 7 months for REXUS experiments (from selection to experiment results).

The rockets and balloons are both launched from SSC's Esrange Space Centre, near Kiruna, Sweden.

The REXUS/BEXUS Programme was formalised in 2007 and is now entering its 13 th cycle. At the time of writing, the call for applications is open until the 14th of October.

\section{Fly a Rocket! (FaR)}

The FaR Programme is realised under an agreement between the ESA Education office, the Norwegian Centre for Space Related Education (NAROM) and the Norwegian Space Agency. This programme gives individual students the opportunity to participate in an online training course before attending a one-week intensive sounding rocket campaign at the Andøya Space Centre in Northern Norway.

During the campaign students are offered the opportunity to apply the theoretical information they learnt during the online course, as well as during dedicated lectures. The students are organized into disciplines teams (GPS \& Simulation, Telemetry and Data Readout, Payload and Sensor Experiment) and prepare the payload and launch facilities themselves. The execution of the launch operations is completely executed by the students (under close supervision of the Andøya Space Centre staff).

This is the only hands-on programme for which students apply as individuals.

The programme is currently ran biennially, and up to 24 students are selected to participate in each edition. The duration of one cycle of the programme is approximately 10 months (from selection until results).

This programme is designed for undergraduate students in their first and second year of university studies, and it is conceived to 'fill the gap' between high-school activities and the more advanced hands-on activities of the office.
The pilot cycle was completed in 2017 , and the second edition was completed in 2019. The next call for proposals is expected to be announced in summer 2020, with the launch campaign in 2021.

XI. WHAT ARE THE CRITERIA TO PARTICIPATE IN A TRAINING SESSION OR HANDS-ON ACTIVITY AND WHAT DOES THE ESA ACADEMY OFFER STUDENTS?

Each programme, both TLP training sessions and hands-on activities, has its own requirement for the current education level of the students (e.g. Bachelor, master, PhD) and sometimes specific subjects (e.g. engineering, sciences). Many of the hands-on programmes also have requirements on team size and composition.

However, in general to participate in an ESA Academy Programme, and to receive ESA sponsorship (mostly for travels related to key events of the programme), a student must:

- Be a national of an ESA Member State, Slovenia or Canada.

- $\quad$ Be enrolled as a full time student.

- $\quad$ Be between the ages of 18 and 32 (inclusive).

Additionally for the hands-on programmes students must be studying in an ESA Member State, Slovenia or Canada

\section{WHAT ARE THE PARTICIPATION STATISTICS IN THE ACTIVITIES OF THE ESA ACADEMY?}

Since the creation of the ESA Academy in 2016, nearly 2500 students have directly participated in its programmes. The cumulative programme reach (i.e. running total) can be seen in Figure 1.

Beyond the direct participants, it is estimated that thousands of other students have been indirectly reached either through their contribution to the work of the student teams officially selected for participation in the hands-on projects, or through outreach efforts both direct (i.e. by ESA Education) and indirect (i.e. by other students).

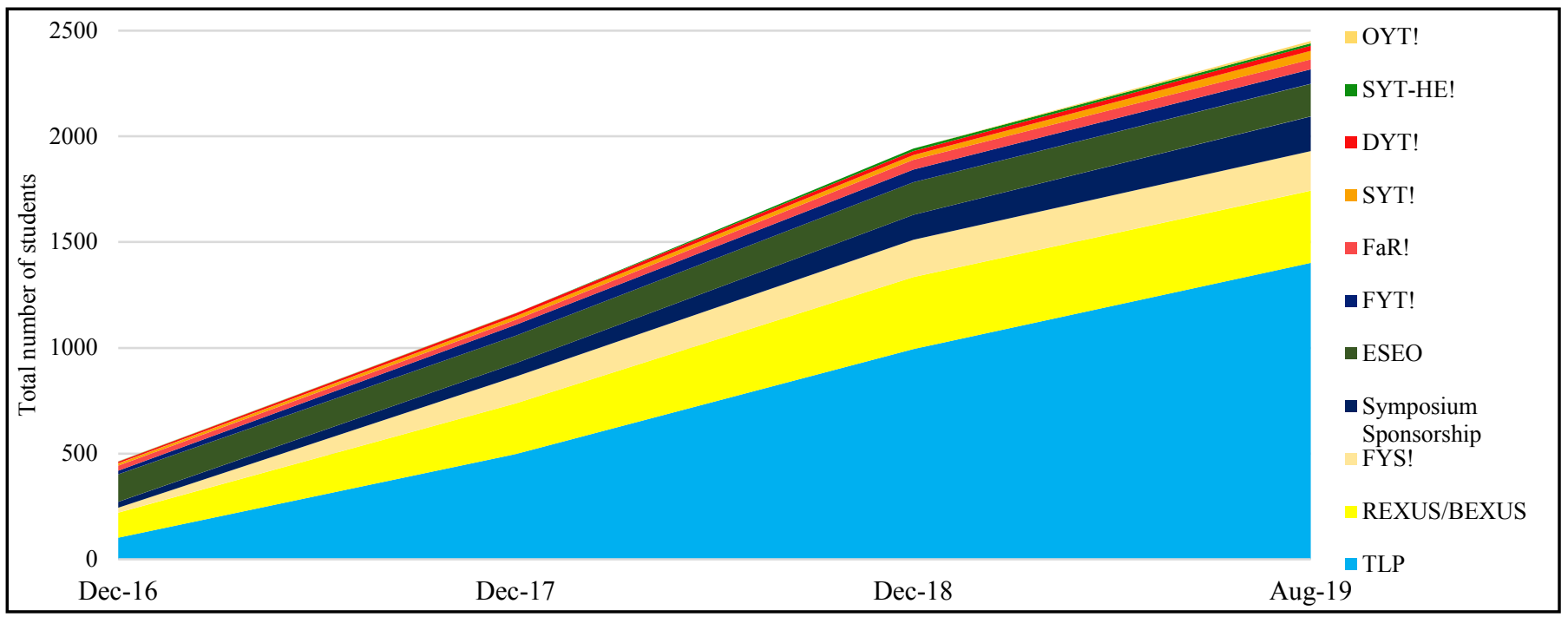

Figure 1: Cumulative participation numbers in ESA Academy programmes (direct programme participations since March 2016) 
From a 2017 survey of the REXUS/BEXUS alumni [8], numerous pieces of anecdotal evidence and through structured TLP feedback, it can be seen that participation in the ESA Academy programmes is well appreciated and helps students further their career and understand the role that they can play in the space industry.

The survey alone showed a wealth of resulting publications, a participant satisfaction rate of $99.1 \%$, and $92 \%$ of the students after their participation increased their interest in pursuing a space related career. At the time of completing the questionnaires, $65 \%$ of the respondents also reported that they were already engaged in space-related employment, distributed in nearly the whole European space sector, and some in relatively high ranking roles.

\section{WHAT HAVE BEEN THE RECENT CHALLENGES AND DEVELOPMENTS FOR THE ESA ACADEMY?}

The ESA Academy is always looking forward to opportunities and challenges that will be faced in the future of the European space sector, and adjusts and develops its offer accordingly.

In the recent past, the ESA Academy has considerably expanded its portfolio of opportunities with the addition of the Training and Learning Programme, which adds significantly to the knowledge transfer from agency and industry experts to students, addressing key issues around transfer and retention of knowledge in Europe.

The TLP itself has also rapidly developed a portfolio of activities based around ESA competencies and European needs, including both strategic and tactical planning.

Furthermore the Academy has added new programmes:

- $\quad$ Fly a Rocket! - which 'fills the gap' between high school activities and more advanced hands-on programmes.

- $\quad$ Orbit Your Thesis! - which takes further advantage of the ease of access to the International Space Station in order to utilise it as an educational platform.

- $\quad$ Spin Your Thesis! - Human Edition - which offers the opportunity to students interested in human space physiology to conduct hands-on experiments on human subjects, and to familiarise with the problematics related to the long-duration human space missions.

Last, but not least, it is important to recall that the ESA Academy, and the Education Office in general, maintains its commitment to equality of opportunity.

\section{WHAT ARE THE FUTURE CHALLENGES/DEVELOPMENTS FOR THE ESA ACADEMY?}

In the future, the ESA Academy will further evolve its educational offer, and will tailor its effort to meet the future needs of the European space sector. The ESA Academy is well placed to build on the mature and solid foundation of its Handson Programme and on the expanding portfolio of training sessions of its Training and Learning Programme.

It is envisaged that the ESA Academy, and the ESA Education Office as a whole, in collaboration with the European space community, will continue to identify and to address upcoming needs and will help to provide the next generations of space professionals with the necessary skills needed to tackle the new challenges. These challenges and needs may include climate research, resource utilization and management, space situation awareness, and future long-term manned missions (return to the Moon and Mars missions). It is envisaged that new opportunities may be created through further fostering of relationships and collaborating with other ESA directorates, and also with industrial, academic, and EU or international partners.

The ESA Education Office aims to develop its long and medium term strategy to support the educational community to prepare for "jobs that have not been created; for technologies that have not yet been invented; to solve problems that have not yet been anticipated" [9].

\section{ACKNOWLEDGMENTS}

The ESA Education Office would like to acknowledge all partners and trainers involved in the ESA Academy programmes, because their enthusiasm and knowledge makes all these opportunities possible.

Furthermore the authors would like to thank all their colleagues of the ESA Academy team, because their competence and dedication are key to ensure students can get the best possible benefit from their participation in the ESA Academy Programme.

\section{REFERENCES}

[1] European Space Agency, "ESA Education Policy ESA/ADMIN/IPOL," (2004)8, Paris, 22 November 2004.

[2] European Space Agency, "ESA Convention," Paris, 30 May 1975.

[3] Wubbo Ockels et al., "ESA Education Office," in Teach Space 2001 International Space Station Education Conference, ESTEC, Noordwijk., 2001.

[4] Isabelle Duvaux-Bechon et al., "The ESA Education Office and Some Current Projects," ESA Bulletin 109, pp. 101-104, February 2002.

[5] European Space Agency, "Advisory Commitee on Education ESA/ADMIN(2002)19," Paris, 2 December 2002.

[6] European Space Agency, "SSETI Express," 13 October 2005. [Online]. Available: https://www.esa.int/Education/SSETI_Express/. [Accessed 5 August 2019].

[7] European Space Agency, “The YES Programme,” 17 July 2013. [Online]. Available: https://www.esa.int/Education/Young_Engineers_Satellites/The_YES programme/. [Accessed 5 August 2019].

[8] Michael Becker et al., "10 Years of the German-Swedish REXUS/BEXUS Student Programme," in 23rd ESA Symposium on Rocket \& Balloon Programmes and releated Research, Visby, Sweden, 2017.

[9] OECD, "The Future of Education and Skills - Education 2030," OECD, Paris, 2018. 